\title{
Die Entwicklung des Europäischen Verwaltungsrechts aus der Perspektive der Handlungsformenlehre
}

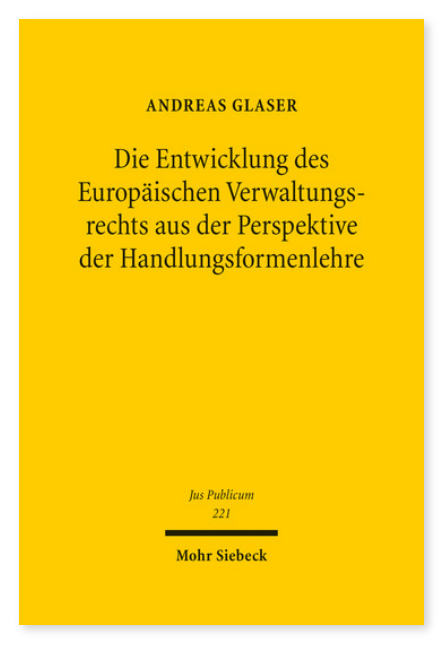

2013. XXXI, 700 Seiten. JusPubl 221

ISBN 978-3-16-152485-1

DOI 10.1628/978-3-16-152485-1

eBook PDF 174,00 €

ISBN 978-3-16-152260-4

Leinen $174,00 €$
In den Rechtsordnungen der EU-Mitgliedstaaten sind den Formen des Verwaltungshandelns bestimmte Rechtsfolgen in Bezug auf das Verwaltungsverfahren, die Wirksamkeit von Verwaltungshandlungen, die Auswirkungen von Rechtsverstößen und den Rechtsschutz zugeordnet. Ausgehend hiervon untersucht Andreas Glaser die Einwirkungen der als Unionsverwaltungsrecht bezeichneten Vorgaben des EU-Rechts auf die jeweilige Handlungsformenlehre des nationalen Rechts. Weitere Schwerpunkte der Analyse bilden die Handlungsformen der EU-Eigenverwaltung auf der Grundlage des Vertrages von Lissabon sowie das Zusammentreffen nationaler und unionaler Handlungsformen im Rahmen des Europäischen Verwaltungsverbundes. Anhand dieser Betrachtungen benennt der Autor übergreifend Übereinstimmungen und Unterschiede zwischen den Rechtsordnungen. Abschließend zeigt er das rechtspolitische Entwicklungspotenzial auf.

Andreas Glaser Geboren 1977; Studium der Rechtswissenschaft an der Justus-Liebig-Universität Gießen; 2005 Promotion an der Universität Bayreuth; seit 2009 Akademischer Rat a. Z. am Institut für deutsches und europäisches Verwaltungsrecht der Ruprecht-Karls-Universität Heidelberg; 2012 Habilitation; 2012/2013 Vertretung des Lehrstuhls für Öffentliches Recht und Verwaltungswissenschaften an der Ludwig-Maximilians-Universität München.
Jetzt bestellen:

https://mohrsiebeck.com/buch/die-entwicklung-des-europaeischen-verwaltungsrechts-aus-der-perspektive-der-

handlungsformenlehre-9783161524851?no_cache=1

order@mohrsiebeck.com

Telefon: +49 (0)7071-923-17

Telefax: $+49(0) 7071-51104$ 